\title{
Hematologic and plasma biochemical reference values of the yellow pond turtle Mauremys mutica and the effects of sex and season
}

Pin-Huan Yu, Pu-Yu Yang, Yun-Shan Chiu and Chau-Hwa Chi

\begin{abstract}
Background: The International Union for Conservation of Nature considers the yellow pond turtle Mauremys mutica to be an endangered species. Hematologic analyses are useful tools for monitoring the health, disease processes, and physiologic status of reptiles by clinicians and conservationists. The objectives of this study were to measure plasma biochemical values in healthy captive yellow pond turtles, determine reference values, and evaluate the effects of sex and season on the results. Blood samples were taken from the jugular vein of 53 adult captive individuals (18 males and 35 females) in four different months that represented summer, winter, fall, and spring in Taiwan. Plasma biochemical assays were performed using an automatic analyzer. Descriptive statistics and distributions of each data variable were analyzed using SAS software.

Results: Hematological and plasma biochemical reference values of the yellow pond turtle were determined in this study. There were no significant sex differences in hematological values; however, there were seasonal differences, and interactions between sex and season were observed. In females, lactate dehydrogenase, uric acid, calcium, cholesterol, and triglyceride concentrations were significantly higher than in males. There were seasonal differences but no sex and season interactions in serum biochemical values.
\end{abstract}

Conclusions: This information can serve as baseline reference data for future health assessment studies of free-ranging and captive M. mutica, and for epidemiologic, conservation, and captive-breeding studies.

Keywords: Blood test; Mauremys mutica; Reference values; Yellow pond turtle

\section{Background}

The yellow pond turtle Mauremys mutica is one of the four native species of turtle in Taiwan. It is also found in China, Japan, and northern and central Vietnam. However, populations are decreasing as a result of habitat loss and collection for the Chinese herbal medicine and pet markets. The International Union for Conservation of Nature considers $M$. mutica to be an endangered species (Asian Turtle Trade Working Group 2000).

Blood analyses are useful, widely used tools that aid in the diagnosis and monitoring of animal health and disease, and in the differentiation of physiologic processes. These techniques have been used with several wildlife species, especially with threatened or endangered

\footnotetext{
* Correspondence: Chie@ntu.edu.tw

Department of Veterinary Medicine, National Taiwan Univ., 1, Roosevelt Road, Sec. 4, Taipei 106, Taiwan
}

populations, and may aid in evaluating ecosystem health (Kenichi et al. 2011). Animals have very complicated and delicate responses to stress that protect against environmental perturbations and which may be disadvantageous to their physiology, psychology, growth, and breeding (Bharath et al. 2012). The blood of reptiles contains nucleated erythrocytes, nucleated thrombocytes, heterophils, eosinophils, basophils, lymphocytes, and monocytes. Hematology is used to detect conditions related to these cells, such as anemia, inflammatory diseases, parasitemias, hematopoietic disorders, and hemostatic alterations (Terry 2006). Blood biochemical profiles are often used to assess the physiologic status of reptilian patients. Factors that affect the hematologic and plasma biochemical values of reptiles include environmental conditions, age, gender, nutrition, season, use of anesthetics, and the physiologic status of the reptile such as dehydration and estrus (Dessauer 1970; Samour et al. 
1986; Lawrence 1987; Terry 2006; Chung et al. 2009). However, baseline hematological and biochemical parameters of $M$. mutica have not yet been published. The purpose of this study was to establish accurate baseline values of clinical laboratory data for $M$. mutica with regard to sex and season. The data presented should be beneficial to the conservative medicine of this endangered species.

\section{Methods}

\section{Subjects and husbandry}

Clinically normal adult males $(n=18)$ and females $(n=35)$ of $M$. mutica were maintained together in an outdoor enclosure at the Laboratory Animal Facility, National Taiwan Univ. (Taipei, Taiwan). The enclosure measured $15 \mathrm{~m}^{2}$, contained three basking areas, had sand as bedding material, and two $4.3-\mathrm{m}^{2}$ ponds. Fresh vegetables, fruit, liver, and commercial pellet food were provided at $2 \%$ of body weight (BW) every 2 to 3 days. The frequency of feeding depended on the weather and appetite. If the food was finished within $10 \mathrm{~min}$, additional food was given. Differences in activity and behaviors like swimming and nesting were recorded, and blood samples were collected in April, August, and November 2010 and in February 2011. BW was measured to the nearest $5 \mathrm{~g}$ with an electric scale, and the maximum straight carapace length was measured to the nearest $1 \mathrm{~mm}$ with vernier calipers each time blood was collected.

\section{Hematologic and plasma chemical assays}

Turtles were sedated with an intramuscular injection of 5 to $10 \mathrm{mg} / \mathrm{kg}$ tiletamine-zolazepam (Zoletil ${ }^{\bullet}$, Virbac, Carros, France), and $1 \mathrm{ml}$ of blood was obtained from the jugular vein using a 29-gauge $\times 12.7$-mm needle. Blood was placed in two tubes of 0.25 and $0.75 \mathrm{ml}$ containing lithium heparin, respectively: $0.75 \mathrm{ml}$ of blood was centrifuged at $2,000 \times g$ for $3 \mathrm{~min}$ to separate the plasma used for biochemistry analysis, and $0.25 \mathrm{ml}$ of blood was used to obtain data on the packed cell volume (PCV), hemoglobin $(\mathrm{Hb})$ concentration, red blood cell $(\mathrm{RBC})$ and white blood cell (WBC) counts, and WBC differential count.

Plasma biochemical assays were performed using an automatic analyzer (VITROS ${ }^{\odot} 350$ Chemistry System, Ortho Clinical Diagnostics, Johnson \& Johnson, Melbourne, Australia). The assays included in the clinical chemistry profile were aspartate aminotransferase (AST), blood urea nitrogen (BUN), calcium, uric acid, cholesterol, creatinine, creatine kinase (CK), glucose, phosphorous, total protein (TP), triglyceride, lactate dehydrogenase (LDH), sodium, potassium, and chloride. Detailed techniques and reference methods applied for each analyte were according to the online datasheet of VITROS ${ }^{\oplus}$ instructions (available at http:// www.orthoclinical.com).

An air-dried blood smear was stained with Liu's stain (Liu's stain A and B, ASK ${ }^{\oplus}$, Taipei, Taiwan), and a manual 100-cell differential count was obtained. WBC and RBC counts were performed using a hemocytometer and Natt and Herick's solution (Terry et al. 2007). Microhematocrit tubes containing ammonium-heparin were filled with blood and centrifuged at $14,800 \times g$ for $3 \mathrm{~min}$ to determine the PCV. Hb was assayed by the cyanmethemoglobin method. The mean cell volume (MCV), mean cell $\mathrm{Hb}$ $(\mathrm{MCH})$, and mean cell $\mathrm{Hb}$ concentration $(\mathrm{MCHC})$ were calculated using the formulae: $\mathrm{MCV}=(\mathrm{PCV} / \mathrm{RBC}) \times 10$; $\mathrm{MCH}=(\mathrm{Hb} / \mathrm{RBC}) \times 10 ;$ and $\mathrm{MCHC}=(\mathrm{Hb} / \mathrm{PCV} \%) \times 100$.

\section{Statistical analysis}

Outliers were deleted if the difference between the outlying value and adjacent value exceeded one third of the total range of all values. In addition, values over three-times the standard deviation (SD) were deleted (Lumsden et al. 1978; Healy 1979; Harris et al. 1995; Solberg 1999).

Descriptive statistics and distributions for each data variable were examined using SAS, vers. 8.2 (SAS Institute, Cary, NC, USA). Mean values and the SD were calculated for males and females in each season. A Kolmogorov-Smirnov test $(p<0.05)$ was used to ascertain whether the data were from a Gaussian distribution (Lumsden et al. 1978). If the data were from a Gaussian distribution, a two-way analysis of variance (ANOVA) $(p<0.05)$ was used on all blood and biochemical variables to test for effects of season, sex, and the interaction of sex and season. If the data were not from a Gaussian population, the data were log-transformed before being analyzed. Scheffe's $F$ test was used for post hoc group comparisons. For results that did not significantly differ between the sexes, reference values were determined from values pooled from male and female turtles in each season (Lumsden et al. 1978; Chung et al. 2009).

When the data were from a Gaussian distribution, reference intervals were defined by minimum and maximum values for groups of fewer than 40 samples and by central $95 \%$ percentiles (mean $\pm 2 \mathrm{SD}$ ) for groups of more than 40 samples (Solberg 1999).

\section{Results}

Weather, habitat, body condition, and reproductive performance

According to the Central Weather Bureau of Taiwan, monthly average temperatures in Taipei in April, August, and November 2010 and February 2011 were $20.7^{\circ} \mathrm{C}$, $30.0^{\circ} \mathrm{C}, 21.5^{\circ} \mathrm{C}$, and $16.9^{\circ} \mathrm{C}$, respectively. Monthly average humidity levels were $78 \%, 72 \%, 75.4 \%$, and $78 \%$, respectively. 
Table 1 Sex and seasonal differences and the interaction of sex with season in the hematology of captive adult Mauremys mutica

\begin{tabular}{|c|c|c|c|c|c|c|c|c|c|c|c|c|}
\hline \multirow[b]{2}{*}{ Analyte } & \multirow[b]{2}{*}{ Spring ${ }^{a}$} & \multirow[b]{2}{*}{ Summer ${ }^{a}$} & \multicolumn{3}{|c|}{ Seasonal differences } & \multirow[b]{2}{*}{$p$ value } & \multirow[b]{2}{*}{ Male } & \multicolumn{2}{|c|}{ Sex differences } & \multirow[b]{2}{*}{$p$ value } & \multicolumn{2}{|c|}{ Sex $\times$ season } \\
\hline & & & Fall $^{a}$ & Winter $^{a}$ & $F$ value $^{b}$ & & & Female & $\overline{F \text { value }}$ & & $F$ value & $p$ value \\
\hline $\operatorname{RBCs}\left(10^{6} / \mu \mathrm{l}\right)$ & - & $\mathrm{H}$ & - & - & $15.164^{c}$ & ** & - & - & nsd & nsd & nsd & nsd \\
\hline PCV (\%) & $\mathrm{H}$ & - & - & - & 22.34 & $* *$ & - & - & nsd & nsd & nsd & nsd \\
\hline $\mathrm{Hb}(\mathrm{g} / \mathrm{dl})$ & $\mathrm{H}$ & - & - & - & 14.809 & $* *$ & - & - & nsd & nsd & nsd & nsd \\
\hline WBCs $(\mu l)$ & - & - & - & $\mathrm{H}$ & 10.366 & $* *$ & - & - & nsd & nsd & nsd & nsd \\
\hline Heterophils $(\mu \mathrm{l})$ & - & $\mathrm{H}$ & - & - & 3.084 & $* *$ & - & - & nsd & nsd & nsd & nsd \\
\hline Lymphocytes $(\mu l)$ & - & $\mathrm{H}$ & - & L & 6.469 & $* *$ & - & - & nsd & nsd & nsd & nsd \\
\hline Basophils $(\mu \mathrm{l})$ & $\mathrm{H}$ & - & - & - & 11.576 & $* *$ & - & - & nsd & nsd & nsd & nsd \\
\hline Eosinophils $(\mu \mathrm{l})$ & - & - & & - & nsd & nsd & - & - & nsd & nsd & nsd & nsd \\
\hline Monocytes $(\mu \mathrm{l})$ & - & - & L & $\mathrm{H}$ & 3.147 & $* *$ & - & - & nsd & nsd & 3.108 & $*$ \\
\hline
\end{tabular}

${ }^{a}$ Means significantly higher $(\mathrm{H})$ or lower (L) than for the other sex or the other seasons. ${ }^{\mathrm{b}}$ Two-way ANOVA $(p<0.05) .{ }^{\mathrm{c}}$ nsd, no significant difference. ${ }^{* *} p<0.01$. RBCs, red blood cells; PCV, packed cell volume; $\mathrm{Hb}$, hemoglobin; WBCs, white blood cells.

Table 2 Hematological and plasma biochemical reference values for male captive adult Mauremys mutica in February, April, August, and November

\begin{tabular}{|c|c|c|c|c|}
\hline Variable & February & April & August & November \\
\hline $\mathrm{Hb}(\mathrm{g} / \mathrm{dl})$ & 4.1 to 7.6 & 4.9 to 8.8 & 2.7 to 7.8 & 4.7 to 7.2 \\
\hline PVC (\%) & 20 to 46 & 26 to 40 & 15 to 36 & 22 to 30 \\
\hline $\operatorname{RBCs}\left(10^{6} / \mu \mathrm{l}\right)$ & 0.33 to 0.83 & 0.55 to 1.11 & 0.15 to 1.31 & 0.4 to 0.91 \\
\hline WBCs $(\mu l)$ & 2,220 to 15,400 & 2,220 to 27,800 & 3,400 to 11,600 & 2,000 to 14,000 \\
\hline Heterophils ( $\mu \mathrm{l})$ & 38 to 82 & 37 to 87 & 35 to 77 & 41 to 76 \\
\hline Lymphocytes $(\mu l)$ & 4 to 41 & 7 to 33 & 12 to 38 & 13 to 37 \\
\hline Basophils ( $\mu \mathrm{l})$ & 0 to 37 & 1 to 30 & 0 to 29 & 5 to 34 \\
\hline Eosinophils $(\mu \mathrm{l})$ & 0 to 1 & 0 to 2 & 0 to 1 & 0 \\
\hline Monocytes $(\mu \mathrm{l})$ & 3 to 15 & 1 to 12 & 1 to 12 & 0 to 9 \\
\hline AST (U/I) & 39 to 229 & 58 to 332 & 60 to 230 & 41 to 133 \\
\hline LDH (IU/I) & 759 to 4,265 & 870 to 8,102 & 730 to 4,956 & 787 to 3,385 \\
\hline BUN (mg/dl) & 1 to 16 & 3 to 16 & 1 to 19 & 1 to 11 \\
\hline Calcium (mg/dl) & 8.8 to 14.6 & 8.7 to 16.2 & 8.5 to 12.5 & 8.3 to 12.1 \\
\hline Phosphorus (mg/dl) & 1.9 to 3.4 & 1.7 to 4.9 & 2.8 to 4.3 & 2.1 to 3.1 \\
\hline CK (U/l) & 153 to 1,240 & 230 to 691 & 97 to 1426 & 119 to 587 \\
\hline Uric acid (mg/dl) & 0.3 to 1.1 & 0.5 to 1 & 0.7 to 1.7 & 0.4 to 0.8 \\
\hline Creatinine (mg/dl) & 0.1 to 0.2 & 0.1 to 0.4 & 0.1 to 0.3 & 0.1 \\
\hline Glucose (mg/dl) & 34 to 87 & 52 to 125 & 41 to 102 & 32 to 89 \\
\hline Total protein (g/dl) & 3 to 5.9 & 3.5 to 6.3 & 2.1 to 7 & 2.1 to 4.4 \\
\hline Triglyceride (mg/dl) & 37 to 464 & 33 to 913 & 27 to 304 & 5 to 542 \\
\hline Cholesterol (mg/dl) & 80 to 224 & 83 to 286 & 61 to 149 & 62 to 131 \\
\hline Sodium (mmol/l) & 131 to 137 & 131 to 137 & 113 to 137 & 122 to 134 \\
\hline Potassium (mmol/l) & 2.9 to 3.8 & 3.5 to 4.6 & 4.5 to 8.9 & 3.2 to 5.8 \\
\hline Chloride $(\mathrm{mmol} / \mathrm{l})$ & 101 to 110 & 101 to 110 & 102 to 111 & 98 to 107 \\
\hline
\end{tabular}

$\mathrm{Hb}$, hemoglobin; PCV, packed cell volume; RBCs red blood cells; WBCs, white blood cells; AST, aspartate aminotransferase; LDH, lactate dehydrogenase; BUN, blood urea nitrogen; CK, creatine kinase. 
All turtles had overwintered from December to late February, spending most of their time in the water. But during very cold periods, they would leave the water and 'huddle' together in a gap and sometimes bury themselves in the sand. At such times, their activity and appetite decreased but had returned to normal by March, at the onset of spring. Some minor wounds were discovered during the mating season between late March and September, attributable to copulation and fighting activities; however, no major injuries were found. During the study period, all females were gravid. Gravid females reproduce normally between May and early October according to a previously described timeline (Dessauer 1970). The average BW of all turtles was 790.6 (range, $1,160$ to 575$) \mathrm{g}$. The average carapace length was 17.7 (range, 20.3 to 15.7 ) $\mathrm{cm}$.

\section{Hematology}

There were no significant differences in hematological values between males and females. For both sexes, values of the PCV, $\mathrm{Hb}$, and basophil differential count were significantly higher in spring. Values of RBCs, and heterophil and lymphocyte differential counts were significantly higher in summer. Values of the monocyte differential count were significantly lower in fall. Values for WBCs and the monocyte count were significantly higher in winter. Values for the lymphocyte count were significantly lower in winter (Table 1). There were interactions between sex and season for the monocyte count. Hematological reference values for males and females of M. mutica in spring, summer, fall, and winter are respectively given in Tables 2 and 3.

\section{Clinical chemistry}

In females, LDH, uric acid, calcium, cholesterol, and triglyceride concentrations were significantly higher than those in males. Males had significantly higher CK and AST concentrations. Both sexes showed significantly higher concentrations of AST, BUN, calcium, cholesterol, triglyceride, glucose, and total protein in spring; concentrations of phosphorus, uric acid, creatinine, potassium, and chloride were significantly higher in summer.

Table 3 Hematological and plasma biochemical reference values for female captive adult Mauremys mutica in February, April, August, and November

\begin{tabular}{|c|c|c|c|c|}
\hline Variable & February & April & August & November \\
\hline $\mathrm{Hb}(\mathrm{g} / \mathrm{dl})$ & 3.3 to 8.2 & 3.8 to 9.4 & 3.7 to 7.2 & 3.9 to 8.2 \\
\hline PVC (\%) & 19 to 41 & 21 to 47 & 18 to 42 & 21 to 34 \\
\hline $\operatorname{RBC}\left(10^{6} / \mu \mathrm{l}\right)$ & 0.34 to 0.84 & 0.38 to 1.2 & 0.41 to 1.16 & 0.24 to 0.84 \\
\hline WBC $(\mu \mathrm{l})$ & 3,330 to 26,400 & 3,552 to 21,200 & 2,200 to 26,400 & 2,600 to 15,400 \\
\hline Heterophils $(\mu l)$ & 34 to 74 & 29 to 75 & 41 to 92 & 36 to 76 \\
\hline Lymphocytes ( $\mu \mathrm{l})$ & 8 to 34 & 1 to 41 & 6 to 39 & 12 to 30 \\
\hline Basophils $(\mu \mathrm{l})$ & 0 to 35 & 0 to 36 & 0 to 25 & 0 to 35 \\
\hline Eosinophils $(\mu l)$ & 0 to 2 & 0 to 3 & 0 to 2 & 0 to 1 \\
\hline Monocytes $(\mu \mathrm{l})$ & 2 to 12 & 1 to 22 & 1 to 10 & 1 to 11 \\
\hline AST (U/I) & 42 to 147 & 53 to 213 & 65 to 186 & 48 to 116 \\
\hline $\mathrm{LDH}(\mathrm{IU} / \mathrm{I})$ & 823 to 2,658 & 744 to 8,468 & 635 to 2,474 & 759 to 3,327 \\
\hline BUN (mg/dl) & 1 to 14 & 2 to 22 & 1 to 17 & 1 to 9 \\
\hline Calcium (mg/dl) & 7.5 to 15.5 & 6.6 to 23 & 7.7 to 19.7 & 7.7 to 14.8 \\
\hline Phosphorus (mg/dl) & 1.9 to 3.8 & 1.8 to 5.3 & 2.7 to 5.2 & 2.3 to 3.3 \\
\hline CK (U/I) & 74 to 745 & 176 to 654 & 71 to 417 & 57 to 713 \\
\hline Uric acid (mg/dl) & 0.3 to 1.2 & 0.6 to 1.5 & 0.5 to 1.3 & 0.4 to 1 \\
\hline Creatinine $(\mathrm{mg} / \mathrm{dl})$ & 0.1 & 0.1 to 0.4 & 0.1 to 0.3 & 0.1 \\
\hline Glucose (mg/dl) & 28 to 71 & 42 to 116 & 32 to 126 & 37 to 86 \\
\hline Total protein (g/dl) & 2 to 4.4 & 2.1 to 6.1 & 1.7 to 5.6 & 1.9 to 3.7 \\
\hline Triglyceride (mg/dl) & 65 to 785 & 63 to 877 & 41 to 409 & 78 to 549 \\
\hline Cholesterol (mg/dl) & 71 to 167 & 66 to 285 & 113 to 223 & 70 to 170 \\
\hline Sodium (mmol/l) & 127 to 136 & 121 to 136 & 112 to 143 & 122 to 133 \\
\hline Potassium (mmol/l) & 2.7 to 5.7 & 3.3 to 5.3 & 4.4 to 6.2 & 3.3 to 6.2 \\
\hline Chloride (mmol/l) & 98 to 107 & 96 to 109 & 96 to 112 & 98 to 107 \\
\hline
\end{tabular}


The concentration of total protein was significantly lower in fall. The concentration of sodium was significantly lower in winter and was significantly higher in winter (Table 4). The plasma biochemical reference values for males and females of $M$. mutica in spring, summer, fall, and winter are respectively given in Tables 3 and 4 .

\section{Discussion}

Weather patterns in Taiwan can be divided into two seasons: summer and winter. Therefore, we chose the months with the highest and lowest average temperatures to investigate seasonal variations in blood parameters. In addition, spring was included in order to determine the effect of reproduction on reference values, and fall refers to the specific time period 2 to 3 months before turtles began overwintering.

AST, glucose, total protein, cholesterol, and triglyceride values peaked in spring, which may have been due to higher copulation activity and egg production during this period (Cheng et al. 2010). Tissue injury and mating stress caused by copulation may have resulted in increased AST and glucose values (Terry et al. 2007). There were significant differences in calcium, cholesterol, and triglyceride values between the sexes and among seasons. Higher values in females than in males, and in mating than in non-mating seasons are consistent with the occurrence of egg production and vitellogenesis (Dessauer 1970; Jackson et al. 1974; Anderson et al. 1997; Christopher 1999; Zaias et al. 2006), because higher circulating calcium will support the demand for egg-shell production, and circulating protein, cholesterol, and triglyceride are main materials for follicular development.

Increased metabolic activity may be reflected in increased enzyme activity in plasma (Christopher et al. 1999) and vice versa. The significantly higher heterophil count in summer may have been due to increased metabolic activity, fighting, feeding, and copulation behaviors which cause tissue damage and inflammation (Terry 2006). In addition, the higher AST and CK values may indicate muscle and tissue injury resulting from the above-described activities and the higher metabolic rate of males than females of $M$. mutica. (Dickison et al. 2002; Chung et al. 2009). The significantly lower total protein value in fall and significantly lower glucose value in winter may have been due to lower activity levels and metabolic rate.

Given that proteins may serve as an energy source during hibernation, chelonians will produce and store nitrogenous wastes in the bladder. During this time, BUN values are elevated, and osmolarity increases to prevent water loss. After hibernation, the BUN value of chelonians decreases as water intake increases (Dessauer 1970; Wallace et al. 1970; Christopher et al. 1994; Chung et al. 2009). This may explain the elevated BUN observed in $M$. mutica in early spring. In addition, elevated BUN values in spring and high phosphorus and uric acid levels in summer may be explained by increased food consumption and a higher level of nitrogenous waste being discharged during warmer seasons (Terry 2006).

Table 4 Sex and seasonal differences and interaction of sex with season in the plasma biochemistry of captive adult Mauremys mutica

\begin{tabular}{|c|c|c|c|c|c|c|c|c|c|c|c|c|}
\hline \multirow[b]{2}{*}{ Analyte } & \multirow[b]{2}{*}{ Spring $^{a}$} & \multirow[b]{2}{*}{ Summer ${ }^{a}$} & \multicolumn{3}{|c|}{ Seasonal differences } & \multirow[b]{2}{*}{$p$ value } & \multirow[b]{2}{*}{ Male } & \multicolumn{2}{|c|}{ Sex differences } & \multirow[b]{2}{*}{$p$ value } & \multicolumn{2}{|c|}{ Sex $\times$ season } \\
\hline & & & Fall $^{a}$ & Winter $^{\mathrm{a}}$ & $F$ value $^{b}$ & & & Female & $F$ value & & $F$ value & $p$ value \\
\hline AST (U/I) & $\mathrm{H}$ & - & - & - & $47.805^{c}$ & ** & $\mathrm{H}$ & - & 11.197 & 0.01 & nsd & nsd \\
\hline $\mathrm{LDH}(\mathrm{IU} / \mathrm{I})$ & - & - & - & - & nsd & nsd & - & $\mathrm{H}$ & 6.556 & 0.01 & nsd & nsd \\
\hline BUN (mg/dl) & $\mathrm{H}$ & - & - & - & 42.358 & $* *$ & - & - & nsd & nsd & nsd & nsd \\
\hline Calcium (mg/dl) & $\mathrm{H}$ & - & - & - & 5.584 & $* * *$ & - & $\mathrm{H}$ & 18.037 & 0 & nsd & nsd \\
\hline Phosphorus (mg/dl) & - & $\mathrm{H}$ & - & - & 72.936 & $* *$ & - & - & nsd & nsd & nsd & nsd \\
\hline CK (IU/I) & - & - & - & - & nsd & nsd & $\mathrm{H}$ & - & 20.478 & 0 & nsd & nsd \\
\hline Uric acid (mg/dl) & - & $\mathrm{H}$ & - & - & 41.521 & $* *$ & - & $\mathrm{H}$ & 7.878 & 0.005 & nsd & nsd \\
\hline Creatinine (mg/dl) & - & $\mathrm{H}$ & - & - & 41.603 & $* *$ & - & - & nsd & nsd & nsd & nsd \\
\hline Glucose (mg/dl) & $\mathrm{H}$ & - & & $\mathrm{L}$ & 6.954 & $* *$ & - & - & nsd & nsd & nsd & nsd \\
\hline Total protein (g/dl) & $\mathrm{H}$ & - & L & - & 28.378 & $* *$ & $\mathrm{H}$ & - & 7.791 & 0.006 & nsd & nsd \\
\hline Triglyceride (mg/dl) & $\mathrm{H}$ & - & - & - & 53.135 & $* *$ & - & $\mathrm{H}$ & 28.053 & 0 & nsd & nsd \\
\hline Cholesterol (mg/dl) & $\mathrm{H}$ & - & - & - & 31.098 & $* *$ & - & $\mathrm{H}$ & 12.034 & 0.01 & nsd & nsd \\
\hline Sodium (mmol/l) & - & - & $L$ & $\mathrm{H}$ & 6.293 & $* * *$ & - & - & nsd & nsd & nsd & nsd \\
\hline Potassium (mmol/l) & - & $\mathrm{H}$ & - & - & 59.339 & $* *$ & - & - & nsd & nsd & nsd & nsd \\
\hline Chloride (mmol/l) & - & $H$ & - & - & 24.152 & ** & - & - & nsd & nsd & nsd & nsd \\
\hline
\end{tabular}

${ }^{\mathrm{a}}$ Means significantly higher $(\mathrm{H})$ or lower $(\mathrm{L})$ than for the other sex or the other seasons. ${ }^{\mathrm{b}}$ Two-way ANOVA $(p<0.05) .{ }^{\mathrm{c}}$ nsd, no significant difference. ${ }^{*} p<0.05$;

** $p<0.005 ;{ }^{* * *} p<0.001$. Abbreviations of analytes are defined in the footnotes of Table 2 . 
Dietary sodium is absorbed from the intestines and transported to the kidneys where it is excreted or resorbed depending on a reptile's need for sodium. Reptilian sodium and potassium metabolism involves an active renin-angiotensin system with direct action on osmoregulation (Terry 2006). The significantly higher sodium level in winter may be explained by greater water loss or lower water intake during the winter because turtles spend less time in the water and more time on land in very cold periods. Serum potassium levels can be affected by dietary potassium intake, gastrointestinal potassium loss, and renal secretion (Terry 2006). In this study, significantly higher potassium levels in summer may have been due to greater food intake in the warmer time period. Blood chloride concentrations provide the least clinically useful information about electrolytes (Terry 2006). Thus, significantly higher chloride concentrations during summer may be of little use for the indicating an animal's condition.

In the authors' experience, blood sampling from the jugular vein of $M$. mutica was relatively difficult, compared to other chelonians of the same size. Identification of the jugular vein was complicated by the thick, wrinkled, green skin. Therefore, the use of a 29-guage needle increased the likelihood of successful venipuncture. Hemolysis was rarely encountered because the blooddrawing process was performed with care. However, the difficulty of sampling limited the size of $M$. mutica individuals that could be used for blood sampling and reduced the available sample size.

\section{Conclusions}

The hematologic and blood biochemical data from this study provide useful ranges for evaluating the health status of $M$. mutica. The data reported here were found to be comparable to previously published data for other native turtle species in Taiwan (Chung et al. 2009). Reference values for $M$. mutica obtained in this study should be of benefit to future clinical and conservation work on the endangered yellow pond turtle.

\section{Competing interests}

The authors declare that they have no competing interests.

\section{Authors' contributions}

PHY participated in the design of the study and drafted the manuscript. PYY participated in the design of the study and performed the statistical analysis. YSC participated in the sequence alignment. CHC conceived the study and participated in its design and coordination. All authors read and approved the final manuscript.

\section{Acknowledgements}

The authors acknowledge the Forestry Bureau, Council of Agriculture, Executive Yuan and National Taiwan Univ. Veterinary Hospital for supporting this research.

\section{References}

Anderson NL, Ray FW, Ron H (1997) Hematology and clinical chemistry reference ranges for clinically normal, captive New Guinea snapping turtle (Elseya novaeguineae) and the effects of temperature, sex, and sample type. J Zool Wildl Med 28:394-403

Asian Turtle Trade Working Group (2000) Mauremys mutica. In: IUCN 2011. IUCN Red list of threatened species. Version 2011. 1. Available at www.iucnredlist.org Accessed 17 Oct. 2011

Bharath KV, Jiang IF, Shih HY, Lee DN, Weng CF (2012) Respiratory burst activity in head kidney and spleen leukocytes of tilapia (Oreochromis mossambicus) under acute osmotic stress. Zool Stud 51:1290-1297

Cheng YY, Chen TY, Yu PH, Chi CH (2010) Observations on the female reproductive cycles of captive Asian yellow pond turtles (Mauremys mutica) with radiography and ultrasonography. Zoo Biol 29:50-58

Christopher MM (1999) Physical and biochemical abnormalities associated with prolonged entrapment in a desert tortoise. J Wild Dis 35:361-366

Christopher MM, Brigmon R, Jacobson E (1994) Seasonal alternation in plasma hydroxybutyrate and related biochemical parameters in the desert tortoise (Gopherus agassizii). Compar Biochem Physiol 108A:303-310

Christopher MM, Berry KH, Wallis IR, Nagy KA, Henen BT, Peterson CC (1999) Reference intervals and physiologic alterations in hematologic and biochemical values of free-ranging desert tortoises in the Mojave desert. J Wildl Dis 35:212-238

Chung CS, Cheng CH, Chin SC, Lee AH, Chi CH (2009) Morphologic and cytochemical characteristics of Asian yellow pond turtle (Ocadia sinensis) blood cells and their hematologic and plasma biochemical reference values. J Zool Wild Med 40:76-85

Dessauer HC (1970) Blood chemistry of reptiles: physiological and evolutionary aspects. In: Gans C, Parsons TS (eds) Biology of the reptilian. Academic, New York, pp 1-54

Dickison VM, Jarchow JL, Trueblood MH (2002) Hematology and plasma biochemistry reference range values for free-ranging desert tortoises in Arizona. J Wild Dis 38:143-153

Harris EK, Boyd JC (1995) Statistical bases of reference values in laboratory medicine. Marcel Dekker, New York

Healy MJR (1979) Outliers in clinical chemistry quality-control schemes. Clin Chem 40:675-677

Jackson CG, Holcomb CM, Jackson MM (1974) Aortic calcification, serum calcium, magnesium, sodium and cholesterol in Gopherus polyphemus. Compar Biochem Physiol 49A:603-605

Kenichi T, Yoshinori T, Yoshihito A, Yuko K, Yumi U (2011) Plasma biochemical reference values in clinically healthy captive bearded dragons (Pogona vitticeps) and the effects of sex and season. Vet Clin Pathol 40:368-373

Lawrence K (1987) Seasonal variation in blood biochemistry of long term captive Mediterranean tortoises (Testudo graeca and T. hermanni). Res Vet Sci 42:379-383

Lumsden JH, Mullen K (1978) On establishing reference values. Can J Compar Med 42:293-301

Samour JH, Hawkey CM, Pugsley S, Ball D (1986) Clinical and pathologic findings related to malnutrition and husbandry in captive giant tortoises (Geochelone spp.). Vet Rec 118:299-302

Solberg HE (1999) Establishment and use of reference values. In: Carl AB, Edward RA (eds) Tietz textbook of clinical chemistry, 3rd edn. WB Saunders, Philadelphia, PA, pp 336-356

Terry WC (2006) Clinical pathology of reptiles. In: Douglus RM (ed) Reptile medicine and surgery, 2nd edn. St Louis, MO, Saunders Elsevier, pp 453-470

Terry WC, Christine KE (2007) Hematology of reptiles. In: Terry WC, Christine KE (eds) Avian and exotic animal hematology and cytology, 3rd edn. Ames, IA, Wiley-Blackwell, pp 51-89

Wallace BB, Francis RH (1970) Ureogenesis in chelonian. Compar Biochem Physiol 34:91-100

Zaias J, Terry N, Angela F, Jeff S, Norman HA, Carolyn C (2006) Biochemical and hematologic values for 18 clinically healthy radiated tortoises (Geochelone radiata) on St. Catherines Island. Georgia Vet Clin Pathol 35:321-325

\section{doi:10.1186/1810-522X-52-24}

Cite this article as: Yu et al.: Hematologic and plasma biochemical reference values of the yellow pond turtle Mauremys mutica and the effects of sex and season. Zoological Studies 2013 52:24. 